\title{
Educational Video to Improve Glycemic Control of Type 2 Diabetes Mellitus Patients
}

\author{
Nora Wulandari", Daniek Viviandhari, Afi Seli Febriani \\ Jurusan Farmasi, University of Muhammadiyah Prof. DR. HAMKA, Jakarta \\ Submitted: 02-09-2020 Revised: 21-20-2020 \\ Korespondensi : Nora Wulandari : Email : wulandari.nora@uhamka.ac.id
}

Accepted: 18-12-2020

\begin{abstract}
Glycemic control is a critical point in the management of type 2 diabetes mellitus (T2DM). The limited number of pharmacists in primary health care in Indonesia is one of the reasons that a simple alternative method is needed for managing T2DM patients. Objective: This study aimed to measure the effectiveness of an education diabetes video as a simple method of improving glycemic control of T2DM patients. Methods: This was a quasi-experimental pre-test/post-test study involving T2DM patients from one randomly selected public healthcare centre in East Jakarta. Glycated haemoglobin (A1C) levels were examined before and 12 weeks after the video intervention. Results: Thirty of T2DM patients enrolled in this study. The educational video was found to decrease the A1C level significantly $(p=0.001)$ from an average $\pm S D$ of $7.930 \pm 1.262$ to $5.517 \pm 0.614$. Conclusions: This study found the educational was effective at improving the glycemic control of patients with T2DM. However, further investigation with control group still needed to confirm that the video that did it.
\end{abstract} Keywords: Educational video; glycemic control; T2DM

\section{INTRODUCTION}

Type 2 diabetes mellitus (T2DM) is the most common type of diabetes, which generally characterised by insulin resistance that caused hyperglycaemia. ${ }^{1}$ Diabetes is known to have significant medical and economic consequences. The worldwide prevalence of diabetes among adults (20-79 years of age) was estimated to be $8.8 \%$ in 2010 and is predicted to increase to $10.4 \%$ by 2030.2 According to the 2015 International Diabetes Federation report, the prevalence of diabetes in adults (20-79 years) in Indonesia is $6.2 \%$. The highest incidence of diabetes diagnosed by doctors is in Yogyakarta (2.6\%) and DKI Jakarta $(2.5 \%){ }^{3}$

Chronic hyperglycemia in diabetes is associated with long term damage, dysfunction, and failure of various organ. Appropriate glycemic control and management are crucial to prevent and delay diabetes complications. Poor glycemic control is highly associated with high burden of diabetes complications. ${ }^{4}$ There are many factors related to the glycemic control of diabetes patients. One of them is medication adherence. Higher adherence stated was associated with lower glycated haemoglobin levels as an index of glycemic control. ${ }^{4,5}$
Therapeutic management of T2DM requires an extended period. Additionally, the treatment process is often complicated for patients owing to the management regimen, which covers various aspects, so that treatment becomes unpleasant. Several studies have confirmed that many patients with T2DM poorly comply with their medication regimen. ${ }^{6-10}$ Besides, patient compliance is one of the factors in the treatment of T2DM patients. ${ }^{11,12}$

Correct adherence to medication is a critical factor for the control of diabetes and related comorbidities. ${ }^{9,13}$ A significant barrier to reaching clinical outcomes, however, is poor treatment adherence, which is associated with increased morbidity, mortality, health care spending and hospital admissions. ${ }^{13}$ Nevertheless, a systematic review indicates that the involvement of T2DM patients in their disease management may improve adherence to therapy. ${ }^{14}$

Several interventions have been proved to contribute to enhancing medication adherence. ${ }^{15}$ A systematic review of randomised controlled trials analysing the effectiveness of educational interventions to increase T2DM treatment adherence by patients showed a significant improvement. ${ }^{16}$ 
A study was done in the primary health care with public counselling, and booklet handouts and an increased level of adherence were found after the interventions. ${ }^{7,17}$

Some studies have been conducted using educational videos in various diseases, which were found to be effective at increasing adherence to the medical procedure. ${ }^{18-21}$ Technology-based interventions using the internet for patient education purposes are accessible nowadays.19,21,22 Davis et al., developed a video-based response called Managing Your Diabetes Medicines and reported improved medications adherence based on MMAS-8 score. ${ }^{19}$ A model educational video intervention designed and studied by Yeung et al., using flashcards and a smartphone-activated quick response barcoded educational flashcard video was also found to be effective at improving adherence to diabetes, hypertension and heart failure medications in a low health literacy patients population. $^{21}$

However, technology, such as the internet, is still complicated for most elderly T2DM patients in Indonesia. 7,23 Therefore, such internet-based education is always difficult to apply to the patients in primary health cares in Indonesia. Furthermore, the number of pharmacists employed in primary health cares in Indonesia is also still inadequate to support ideal T2DM management, such as personal counselling for each patient. A report stated that out of 8981 primary health cares in Indonesia, only $17.5 \%$ have a pharmacist. In Jakarta alone, out of 336 primary health cares, only $16.7 \%$ employ pharmacists. $^{24}$ With a complicated management and monitoring therapy in T2DM, it seems sturdy for the pharmacist to be fully involved. Therefore, there is a great need for a simple method that easily be can be done with a limited number of pharmacists to provide education to patients with T2DM in Indonesia so that, even with the limitations of the pharmacist, T2DM patients can still be educated to improve their treatment adherence which expected the good outcome in their glycemic control.
The video-based strategy to improve glycemic control of T2DM has not well documented in Indonesia. The latest study in 2020, used video-based insulin therapy education to increase the knowledge and improve the attitude of diabetes mellitus patient toward insulin therapy. The study did not provide information about the glycemic control improvement caused by the given intervention. ${ }^{25}$ This study provided the glycemic control of the patients before and after the video-based health education, which can be one source of information to study further.

For these reasons, to provide an improved strategy to improve glycemic control of TD2M patients, we propose an educational video that can be shown to the patients as a form of public education in primary health cares. The educational video is one simple way to help patients to improve their knowledge about their medications, which is expected to increase their adherence which expected also improve their glycemic control. This study aimed to assess the effectiveness of this model on improving their glycemic control.

\section{METHODS}

This experimental study was conducted at Duren Sawit primary health care located in East Jakarta. A quasi-experimental pretest/post-test study with a total sampling method was applied to assess the effectiveness of the educational intervention using the educational video to improve the glycemic control of diabetes patients to their therapy. Due to a small population of T2DM on the site of the study, which was only 52 patients, it was not possible to conduct the study with a control group.

In this study, a patient was categorised as T2DM if their fasting plasma glucose was or higher than $126 \mathrm{mg} / \mathrm{dL}$ and/or their A1C level was more than or $6.5 \% .{ }^{26}$ This study used patients with T2DM aged $\geq 18$ years old who have had T2DM for more than one year and use oral antidiabetic (OAD) medication. The inclusion criteria were that the patients must 
speak and understand at least Indonesian language, and they must regularly attend the primary health care for a routine check-up. The structured questions were developed in the form of questionnaire to collect patient's socio-demographic, lifestyle and clinical characteristics; therefore, patients who could not answer the questionnaire independently due to mental illness, dementia or other comorbid medical conditions that were not as stable, patients with hearing and vision problems, and also pregnant women were excluded from this study.

An 8-minute and 47-second educational video was created by authors to educate T2DM patients. The video consists of information about T2DM, management therapy, how to use antidiabetics properly and the effects that patients may get from non-adherence to their treatment plan.

The first data as the pre-test test results from A1C examination were collected before the educational video was shown. After receiving the pre-test data, the educational video was shown to the patients in a meeting room. The same intervention is given three times during the 12 weeks of the study period. At the last intervention, A1C was examined as the post-test measures.

The tools used to collect A1C data in both pre and post-intervention were the i-Chroma ${ }^{\mathrm{TM}}$ A1C level gauge and both examinations conducted by Jakarta Health Laboratory Center (BBLK) of the Indonesian Ministry of Health. Glycemic control was categorised based on the obtained A1C levels. Meanwhile, the glycemic control was divided into two categories based on the A1C level: poor glycemic control with an $\mathrm{A} 1 \mathrm{C}$ level $\geq 6.5 \%$ and good glycemic control with A1C level $<6.5 \% .{ }^{26}$

The normality of each category of preand post-test data in each group was tested using the Kolmogorov-Smirnov test. Descriptive analysis was performed to obtain a distribution frequency as well as the proportion of various variables of the study. These variables were divided into three groups of characteristics, i.e. socio- demographic, clinical and lifestyle characteristics. Paired t-test was used to determine the changes in A1C levels. A $p$-value $<0.05$ was considered to indicate a statistically significant difference.

This study was approved by the Universitas Indonesia Ethics Committee (306/UN2.F1/ETIK/2017). All the subjects provided informed consent before participation.

\section{RESULTS AND DISCUSSION Results}

From July to October 2017, 52 patients were diagnosed with T2DM in Duren Sawit Primary health care in East Jakarta. Seven of them were eliminated because of hearing and vision problems, and nine were eliminated because they missed A1C checks in the second examination and six of them were not present twice in a row at the time of the intervention. Thus, a total of 30 subjects were enrolled in this study.

In the first month, the 30 patients were given the intervention in the form of video education related to T2DM as well as checking the A1C levels. In the second and third subsequent months, patients were again shown the educational video for diabetes. In the fourth month, respondents were re-examined for A1C levels. The characteristics of the respondents in this study are descriptively elaborated based on socio-demographic, clinical and lifestyle factors (Table I).

In regard to socio-demographic characteristics, the patients in this study were mostly female and elderly. They had low, medium and high levels of education and were mostly unemployed. In terms of clinical characteristics, the majority of patients have had T2DM for more than and/or five years of duration, with most having two or more comorbidities. More than $85 \%$ of the patients used more than one OAD with another routine therapy, such as antihypertension and/or antihyperlipidemic drugs. During treatment, $13.3 \%$ of patients claimed to have experienced adverse drug reactions, such as nausea and bloating, after the use of $\mathrm{OAD}$, especially from 
Nora Wulandari, et al

Table I. Patients' characteristics

\begin{tabular}{|c|c|c|}
\hline Variable & $n=30$ & $\%$ \\
\hline \multicolumn{3}{|c|}{ Socio-demographic characteristics } \\
\hline \multicolumn{3}{|l|}{ Sex } \\
\hline Male & 7 & 23.3 \\
\hline Female & 23 & 76.7 \\
\hline \multicolumn{3}{|l|}{ Age } \\
\hline$<60$ years & 10 & 33.3 \\
\hline$\geq 60$ years & 20 & 66.7 \\
\hline \multicolumn{3}{|c|}{ Level of education } \\
\hline Low & 10 & 33.3 \\
\hline Medium & 10 & 33.3 \\
\hline High & 10 & 33.3 \\
\hline \multicolumn{3}{|l|}{ Occupation } \\
\hline Unemployed & 26 & 86.7 \\
\hline Employed & 4 & 13.3 \\
\hline \multicolumn{3}{|c|}{ Clinical characteristics } \\
\hline \multicolumn{3}{|c|}{ Duration of T2DM } \\
\hline$<5$ years & 6 & 20.0 \\
\hline$\geq 5$ years & 24 & 80.0 \\
\hline \multicolumn{3}{|l|}{ Comorbidity } \\
\hline No & 4 & 13.3 \\
\hline 1 & 8 & 26.7 \\
\hline 2 or more & 18 & 60.0 \\
\hline \multicolumn{3}{|l|}{ No. of OAD } \\
\hline 1 & 3 & 10.0 \\
\hline$>1$ & 27 & 90.0 \\
\hline \multicolumn{3}{|l|}{ Use other drugs } \\
\hline No & 4 & 13.3 \\
\hline Yes & 26 & 86.7 \\
\hline \multicolumn{3}{|c|}{ Adverse drug reactions } \\
\hline No & 26 & 86.7 \\
\hline Yes & 4 & 13.3 \\
\hline \multicolumn{3}{|c|}{ Lifestyle characteristics } \\
\hline \multicolumn{3}{|l|}{ Herbs } \\
\hline No & 2 & 6.7 \\
\hline Yes & 28 & 93.3 \\
\hline \multicolumn{3}{|l|}{ Smoking } \\
\hline No & 30 & 100.0 \\
\hline Yes & 0 & 0 \\
\hline \multicolumn{3}{|l|}{ Exercise } \\
\hline No & 7 & 23.3 \\
\hline Yes & 23 & 76.7 \\
\hline \multicolumn{3}{|l|}{ Dietary habit } \\
\hline Non-adjusted & 2 & 6.7 \\
\hline Adjusted & 28 & 93.3 \\
\hline
\end{tabular}


metformin. Based on the lifestyle characteristics of the patients, only $6.7 \%$ used herbs as an alternative therapy, and all the patients claimed to be non-smokers. Besides, they also claimed to do exercise and adjust their dietary habit.

Comparison of the A1C levels before and 12 weeks after the intervention is shown in Error! Reference source not found.II.

The intervention in the form of the educational video was observed to reduce $(P=$ 0.001) the A1C level of the patients, which means it improves the patients' adherence. The percentage of patients with A1C levels of $\geq 6.5 \%$ decreased from $93.33 \%$ before to $10 \%$ in 12 weeks after the intervention.

\section{Discussion}

This study showed that before the education video intervention, the knowledge of T2DM patients about their therapy was poor, which negatively affected their A1C levels. A1C is a gold standard for monitoring long-term blood glucose control for the two or three months before measurement. ${ }^{26}$ In the present study, the T2DM patients in the primary health care had a low level of treatment adherence with poor glycemic control. Based on information from the primary health care, there is only one pharmacist that carries out all the pharmacist duties, both managerial and clinical pharmacy. As mentioned, the availability of pharmacists in a primary health care in Indonesia is still poor. ${ }^{24}$ The number of pharmacists in each primary health care in Indonesia is usually one, which makes it impossible to give personal counselling to every T2DM patient. That is why the patients in the primary health care often accept less education about their medications from the pharmacist.

The present study demonstrates that any education given by pharmacists can increase the adherence of the patients which also reflected in the improvement of the glycemic control of the patients. $7,17,27,28$ Studies using different types of education conducted in 2012 and 2016 showed that there was a significant difference in the average A1C level before and after giving education to patients with T2DM. This studies showed the decreased A1C level of the booklet (16.74\%) while public counselling (19.95\%).7,17 The booklet seems a simple way to educate patients. ${ }^{26}$ However, the audio-visual method suggested by this study could be more easily understood by the patients. The combination of the booklet and public counselling is complicated to achieve with the limited number of pharmacists in primary health cares in Indonesia.

The lack of time to provide education to the patients regarding adherence to their medications, restrictions on insurance coverage for diabetes self-management education and lack of access to health care require health workers, particularly pharmacists, to develop simple methods for educating their patients. ${ }^{7,19}$ However, from the authors' perspective, although internet-based educations or public counselling and public are also considered as simple methods to educate T2DM patients, these methods are less applicable in Indonesia for the time being. The method developed in this study could be more feasible because the pharmacist should only provide the proper material education in the form of the video and administer it during their routine check-up schedule. With that, the limited number of pharmacists should not be an obstacle for T2DM patients receiving education regarding their medications which in the end is expected to enhance their adherence which expected to be beneficial to the glycemic control of the patients.

However, the educational video in this study is less able to display the details of the displayed object clearly, so some management of the therapy might not be pictured clearly. Therefore, there is a need for another simpler method to support this educational video to improve adherence to T2DM treatment.

We conducted this study with three times video-based intervention applied regularly to the patients so it could be making the patients cautious about their therapy, which might affect their glycemic control. 
Table II. Comparison of A1C levels before and 12 weeks after the educational video intervention

\begin{tabular}{lcccc}
\hline \multirow{2}{*}{ Variable } & \multicolumn{2}{c}{ Before } & \multicolumn{3}{c}{ After } \\
\cline { 2 - 5 } & $\mathbf{n}=\mathbf{3 0}$ & $\mathbf{\%}$ & $\mathbf{n}=\mathbf{3 0}$ & $\mathbf{\%}$ \\
\hline$<6.5 \%$ & 2 & 6.67 & 27 & 90 \\
$\geq 6.5 \%$ & 28 & 93.33 & 3 & 10 \\
Mean HbAic \pm SD & $7.930 \pm 1.262$ & \multicolumn{2}{c}{$5.517 \pm 0.641$} \\
$p$ & \multicolumn{3}{c}{$0.001^{\text {a }}$} \\
\hline
\end{tabular}

Note: SD = standard deviation; ${ }^{a}$ The differences were statistically significant according to the paired t-test

However, the given intervention only might be one of the various factors that caused the improvement of glycemic control of the patients. In addition, this study only recorded antidiabetic used in the early intervention. Thus, the possibility of changing the antidiabetic prescribed was not provided, which is part of the limitations of this study.

Also, this study was conducted using a small sample, so it might not give an accurate representation of the whole population of T2DM patients in Indonesia. Thus, further studies involving more patients need to be conducted to get a better picture of the effectiveness of the educational video for diabetes patients in Indonesia. However, this study provides a simple method that can be applied in primary health cares with a limited number of pharmacists to support T2DM management therapy.

\section{CONCLUSIONS}

The developed educational video for T2DM showed statistically significant in improving the glycemic control of the patients. However, further study with a control group is still needed to confirm the effectiveness of the intervention.

\section{CONFLICT OF INTEREST}

The authors declare that they have no competing interest.

\section{REFERENCES}

1. International Diabetes Federation (IDF). International Diabetes Federation -
Type 2 diabetes. International Diabetes Federation.

https://www.idf.org/aboutdiabetes/typ e-2-diabetes.html. Published 2020. Accessed October 18, 2020.

2. Ogurtsova K, Rocha JD, Huang Y, Linnenkamp U, Guariguata L. IDF Diabetes Atlas: Global estimates for the prevalence of diabetes for 2015 and 2040. Diabetes Res Clin Pract. 2017;128:40-50.

3. IDF. Diabetes.; 2015. doi:10.1289/image.ehp.v119.i03

4. American Diabetes Association (ADA). Standars of Medical Care in Diabetes 2020 ADA. Diabetes Care. 2020;42(479):960-1010.

5. Raj GD, Hashemi Z, Soria DC, et al., Adherence to Diabetes Dietary Guidelines Assessed Using a Validated Questionnaire Predicts Glucose Control in Adults With Type 2 Diabetes. Can J Diabetes. 2018;42(1):78-87.

6. Muszbek N, Keskinaslan A, Khan ZM, Cramer JA. The significance of compliance and persistence in the treatment of diabetes, hypertension and dyslipidaemia : a review. Int J Clin Pr. 2008;62(1)(January):76-87.

7. Wulandari N, Viviandhari D, Nurhayati. A Strategic Approach to Increase the Compliance of Patients with Type 2 Diabetes Mellitus, in Unity in Diversity and the Standardisation of Clinical Pharmacy Services: Proceedings of the 17th Asian 
Conference on Clinical Pharmacy (ACCP 2017). In: Elida Z, Junaidi Khotib., Chrismawan A, Syed Azhar Syed S, Charles D. SI, Timothy E. W, eds. Yogyakarta: CRC Press/Balkema; 2017.

8. Sontakke S, Jadhav M, Pimpalkhute S, Jaiswal K, Bajait C. Evaluation of Adherence to Therapy In Patients of Type 2 Diabetes Mellitus. J Young Pharm. 2015;7(4s):462-469.

9. Sufiza Ahmad N, Ramli A, Islahudin F, Paraidathathu T. Medication adherence in patients with type 2 diabetes mellitus treated at primary health clinics in Malaysia. Patient Prefer Adherence. 2013;7:525-530.

10. Ur S, Nazir R, Azmi M, Saleem F. Disease related knowledge, medication adherence and glycaemic control among patients with type 2 diabetes mellitus in Pakistan. Prim Care Diabetes. 2015;10:136-141.

11. Smalls BL, Walker RJ, HernandezTejada MA, Campbell JA, Davis KS, Egede LE. Associations between coping, diabetes knowledge, medication adherence and self-care behaviors in adults with type 2 diabetes. Gen Hosp Psychiatry. 2012;34(4):385-389.

12. García-Pérez LE, Álvarez M, Dilla T, Gil-Guillén V, Orozco-Beltrán D. Adherence to therapies in patients with type 2 diabetes. Diabetes Ther. 2013;4(2):175-194.

13. Bailey CJ, Kodack M. Patient adherence to medication requirements for therapy of type 2 diabetes. Int J Clin Pract. 2011;65(3):314-322.

14. McSharry J, McGowan L, Farmer AJ, French DP. Perceptions and experiences of taking oral medications for the treatment of Type 2 diabetes mellitus: a systematic review and meta-synthesis of qualitative studies. Diabet Med. 2016;33(10):1330-1338.

15. Hugtenburg JG, Timmers L, Elders PJ, Vervloet M, Dijk L Van. Definitions, variants, and causes of non-adherence with medication: a challenge for tailored interventions. Patient Prefer Adherence. 2013;7:675-682.

16. Antoine S-L, Pieper D, Mathes $\mathrm{T}$, Eikermann M. Improving the adherence of type 2 diabetes mellitus patients with pharmacy care: a systematic review of randomised controlled trials. BMC Endocr Disord. 2014;14(1):53.

17. Puspitasari AW, R.Andrajati, A.Bahtiar. Analisis Efektivitas Booklet Obat terhadap Tingkat Kepatuhan Pasien Diabetes Melitus tipe-2. J Manag Pharm Pract. 2013;2:1-7.

18. Kandler L, Tscholl DW, Kolbe M, Seifert B, Spahn DR, Noethiger CB. Using educational video to enhance protocol adherence for medical procedures $t$. BJA. 2016;116(5):662-669.

19. Davis SA, Carpenter D, Cummings DM, et al. Patient adoption of an internet based diabetes medication tool to improve adherence: A pilot study. Patient Educ Couns. 2017;100(1):174-178.

20. Muir KW, Ventura A, Stinnett SS, Enfiedjian A, Allingham RR, Lee PP. Patient Education and Counseling The influence of health literacy level on an educational intervention to improve glaucoma medication adherence. Patient Educ Couns. 2012;87(2):160-164.

21. Yeung DL, Alvarez KS, Quinones ME, et al. Journal of the American Pharmacists Association Low e health literacy $\mathrm{fl}$ ashcards \& mobile video reinforcement to improve medication adherence in patients on oral diabetes, heart failure , and hypertension medications. $J$ Am Pharm Assoc. 2017;57(1):30-37.

22. Tokuda L, Lorenzo L, Theriault A, et al. International Journal of Medical Informatics The utilisation of videoconference shared medical appointments in rural diabetes care. Int J Med Inform. 2016;93:34-41.

23. Soewondo P, Pramono LA. Prevalence, characteristics, and predictors of prediabetes in Indonesia. Med J Indones. 2011;20(4):283-294. 
24. Herman MJ, Supardi S, Yuniar Y. Hubungan ketersediaan tenaga kefarmasian dengan karakteristik puskesmas dan praktik kefarmasian di puskesmas (Analisis Lanjut Data Riset Fasilitas Kesehatan Nasional Tahun 2011). Bul Penelit Sist Kesehat. 2011;16(1):88-98.

25. Ratri DMN, Hamidah KF, Puspitasari AD, Farid M. Video-based health education to support insulin therapy in diabetes mellitus patients. J Public health Res. 2020;9(2):223-226.
26. American Diabetes Association (ADA). Standard of medical care in diabetes 2017. Diabetes Care. 2017;40 (sup 1)(January):s4-s128.

27. Capoccia K, Odegard PS, Letassy N. Medication Adherence With Diabetes Medication. Diabetes Educ. 2016;42(1):34-71.

28. Awodele O, Osuolale JA. Medication adherence in type 2 diabetes patients: Study of patients in alimosho general hospital, Igando, Lagos, Nigeria. Afr Health Sci. 2015;15(2):513-522. 